\title{
Designing computer-based cognitive tools to assist learners to interpret graphs and tables
}

\author{
Brian Ferry, John Hedberg and Barry Harper \\ University of Wollongong
}

This paper reports on the development and evaluation of cognitive tools used to interpret graphs and tables. The development of these tools was informed by research about how learners interpreted graphs and tables. A prototype of the cognitive tools was trialed with a small sample of preservice teachers. This prototype was then improved and used again with a larger sample. Data from individual audit trails of software use, journal entries and interviews with a small sample of preservice teachers were used to evaluate the cognitive tools. The findings showed that the simple, context-specific cognitive tools developed helped to reduce the cognitive load associated with the interpretation of graphs and tables.

\section{Introduction}

Graphs and diagrams are abstract spatial representations (Hegarty, Carpenter, \& Just, 1991) but graphs differ from diagrams because they illustrate relationships among variables whereas diagrams describe processes and structures (Winn, 1987). For the purposes of this study graphs are defined as "forms that illustrate relationships among variables, at least one of which is continuous." (Winn, 1987, p.153). Thus a plot of height against age and a histogram of stream velocity against sediment sizes, and a plot of rainforest area against the name of a country are all graphs.

Tables are displays arranged in rows and columns that illustrate relationships among categorical variables or continuous variables. These rows and columns contain an arrangement of numbers, letters, words, diagrams or a mixture of all of these forms (Winn, 1987, p. 153).

Bowen and Roth (1998) argue that learning to use and interpret graphs is an important skill that scientists have to master because of the central role that graphs play in the practice of science. It is also contended by Roth \& 
McGinn (1997) that competency in the understanding of graphs is an important factor in the comprehension of scientific writing found in journals. A similar argument can be made for tables. Further, the general public also needs to be capable of interpreting graphs and tables as every day they are presented with simple graphs and tables either in the press or in the workplace.

\section{Interpreting graphs and tables}

When learners interpret graphs and tables they read the information contained in the displayed graph or table and relate it to its context. To do this successfully they must be able to read the labels, relate the labels and data to a specific context, described in the accompanying text, and then translate the meaning associated with the display of the data into words (Janvier, 1978). However, this process does not occur in isolation, and as Janvier (1978) asserts, we must be aware that "any pupil has a personal knowledge...a vast background more or less precisely defined is already present in the pupil's mind..." (Janvier p3.6). While the graph conveys definite information which constitutes a definition of the situation, "this is analysed through a process involving a continuous reference to the underlying background" (p.3.6).

Janvier (1978) and Preece (1985) claim that learners experience difficulties in interpreting graphs because of the many modes of representation presented. Apart from a graph, verbal descriptions, tables and formulas are often used to represent the same relationship, and this, he claims, confuses the issue. Their research is supported by Chandler and Sweller (1991) who showed that poorly organised data causes learners to divide their attention among the various pieces of data and this creates cognitive load which in turn leads to inefficient processing of information.

Researchers who have studied how learners interpret graphs and tables mention the following processes: reading a graph or table; deciphering the labels on axes and the headings of columns ; describing the global features of the data such as maxima, minima, slope, turning points, regular trends or the means of data presentation such as picture form, bars, columns, lines; relating the properties of the graphs and charts to information described in accompanying text; applying prior knowledge to aid in the comprehension of the information presented (Appel, 1973; Dugdale, 1986; Pinker, 1981; Mosenthal \& Kirsh, 1991; Preece, 1985; Roth \& Bowen, 1994; Bowen \& Roth, 1998; van Reeuwijk, 1992). The first three processes mentioned relate to reading or mental processing of displayed information 
and the last two points relate to the context in which the information occurs. Jonassen, Peck and Wilson (1999, p 6.) describe these processes as 'meaning-making' and argue that learners need to understand that certain ideas and conventions are shared and agreed upon within a knowledgebuilding community - for example, a community that uses graphs and tables for communication.

\section{Using cognitive tools to interpret graphs and tables}

Cognitive tools have been defined by Jonassen (1992) as: "generalisable tools that can facilitate cognitive processing " (p.2) and students who use such tools learn with the technology rather than from it (Jonassen, Peck \& Wilson, 1999, P. 152.) Cognitive tools can make it easier for learners to process information, but their main "goal is to make effective use of the mental efforts of the learner" (Jonassen, 1996, p.10). Derry and LaJoie (1993) argue that "the appropriate role for a computer system is not that of a teacher / expert, but rather, that of a mind-extension cognitive tool" (p.5).

Jonassen and Reeves (1996) assert that well designed cognitive tools should: represent knowledge (how someone depicts content or personal knowledge); be generalisable (can represent knowledge in different content areas); engage the learner in critical thinking about the subject; assist learners to acquire skills that are generalisable and transferable to other contexts; be simple but powerful in order to encourage deeper thinking and processing of information; be easy to learn - therefore the mental effort needed to learn the software should not exceed the benefits. Research associated with cognitive load, (Chandler \& Sweller, 1991; Sweller, 1994; Sweller \& Chandler, 1994) supports the final two points made by Jonassen and Reeves and suggests that "effective instructional material facilitates learning by directing cognitive resources toward activities that are relevant to learning rather than toward preliminaries to learning" (Chandler \& Sweller, 1991, p.293). This quote describes how we believe cognitive tools should be used to support learner processing of information in graphs and tables. For example, simply arranging the data elements of tables into groups improves learner ability to understand and remember them (Decker \& Wheatley, 1982). Furthermore, if the elements are grouped according to some conceptual structure (for example taxonomy), then their arrangement can reinforce that structure (Rabinowitz \& Mandler, 1983). This view is also supported by Winn (1987, 
p.177) who asserts that "even the simplest spatial organisation of elements into meaningful clusters has the potential to improve learning."

\section{Significance of the study}

This study has significance from three perspectives. First, the findings add to our understanding of the use of cognitive tools designed to assist learners to interpret graphs and tables. The patterns of use and strategies employed by learners should guide future improvements of these tools. Second, the findings may stimulate others to build upon this research and create more sophisticated tools. Third, the findings should add to our understanding of how learners employ cognitive strategies to interpret graphs and tables.

\section{Purpose of the study}

The purpose of this study was to investigate how cognitive tools (developed with HyperCard software) could be used to support learners to process information displayed by graphs and tables. The study had five goals.

1. To identify the cognitive strategies that learners employed when they interpreted graphs and tables.

2. To use the information gathered about the cognitive strategies that the learners employed to inform the design of a prototype of a set of cognitive tools that would assist them to interpret graphs and tables.

3. To trial the protoype of the cognitive tools with a group of learners and describe how they used them.

4. To use the information gathered about learner use of the prototype to inform improvements in the design of the cognitive tools.

5. To describe how learners used the improved version of the cognitive tools.

The subjects of the study were preservice teachers enrolled in teacher education degrees at the University of Wollongong. All had completed a one semester subject in information technology, and could used an Apple Macintosh computer. They could switch it on, use a mouse, load and save software, print out documents, and safely shut down the computer. 


\section{Limitations}

The study was limited to subjects who were preservice teachers. While the research strategies and cognitive tools developed may be applicable to other contexts, and the findings may support and extend the work of previous researchers in the field; specific findings may be unique to the population studied.

The type of cognitive skills involved in the interpretation of graphs and tables were identified through the literature review and then verified by the findings from the first part of the study. These skills fell into three broad categories: reading and comparison skills needed to identify individual values and trends presented by the data displayed in the graphs and tables; reading comprehension skills needed to relate the data to its context; and translation skills needed to articulate the message conveyed by the data into words. These skills are in reality an external manifestation of much a deeper level of cognitive processing within the human brain, but the investigation of this aspect of cognitive processing is beyond the scope of this study.

The cognitive tools developed were used with bar graphs only. While the tools can be applied to line graphs as well as other forms of graphs, no claim can be made about the general applications without further studies with different forms of graphs.

\section{Description of the cognitive tools developed}

The software was developed using HyperCard as an authoring tool because a laboratory of Apple Mcintosh computers was available for the research. If different hardware had been available then other authoring tools could have been used. Figure 1 displays the original opening screen developed for the prototype. The main features are described under the headings of layout and buttons and cognitive tools developed.

\section{Layout and buttons}

On-screen buttons were located down the right hand border of the screen. The descending order of the buttons from top to bottom was in a temporal sequence suggested by a group of three researchers experienced in the field of instructional design (Hedberg, Harper, Cheung, personal communication, November 24th, 1994). 


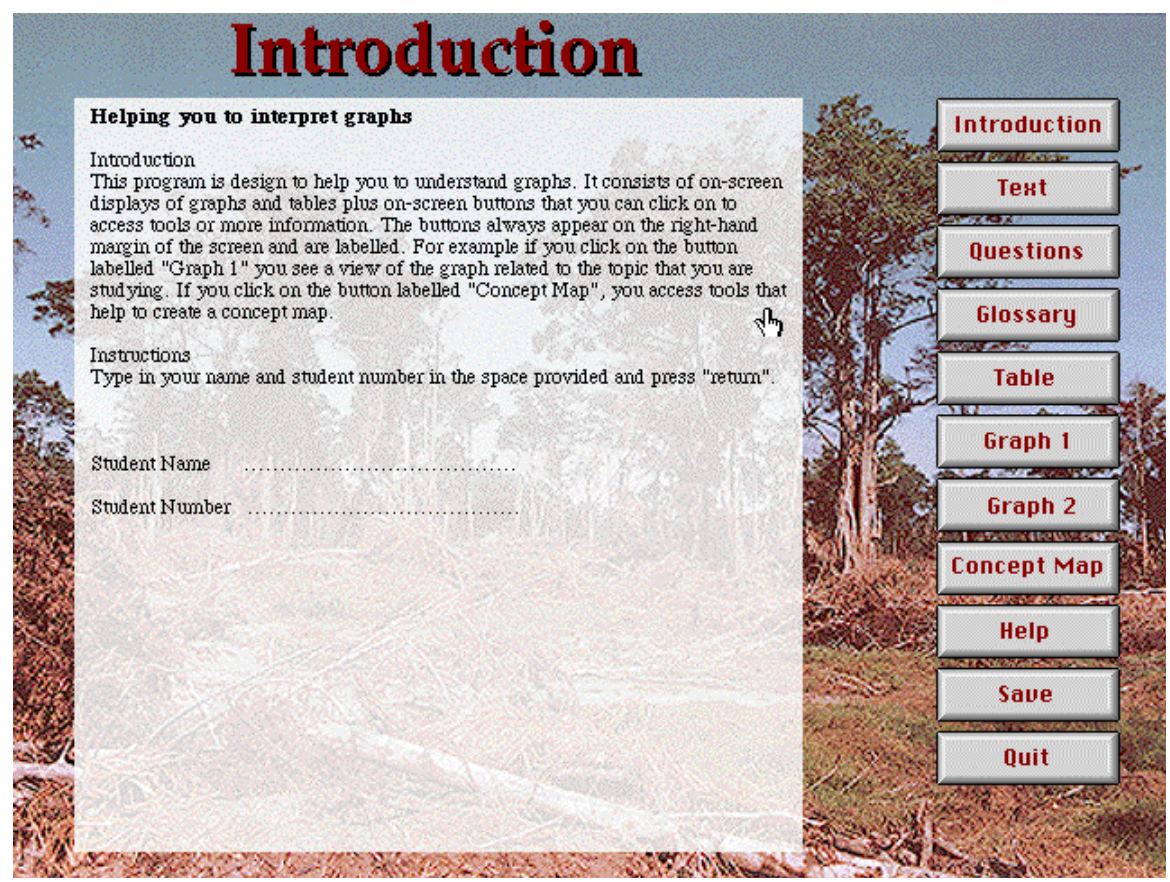

Figure 1: The original opening screen

\section{Cognitive tools developed}

The concept mapping tool was linked to the button labelled concept map. This tool contained a pop-up palette of six buttons which appeared once the concept map button was activated. The six buttons employed by the concept mapping tool mirrored the process recommended by White and Gunstone (1992) and the arrangement of the buttons in the palette was made to follow the instructional sequence which they also recommended. This palette is shown in figure 2 .

\begin{tabular}{|c|c|c|}
\hline \multicolumn{3}{|c|}{ Concept Tools } \\
\hline $\begin{array}{l}\text { SoHstrt } \\
\text { concept }\end{array}$ & link & $\mathbf{w}$ \\
\hline$\underset{\text { eraser }}{G}$ & help & $\begin{array}{l}\text { print } \\
\text { pris }\end{array}$ \\
\hline
\end{tabular}

Figure 2: The original palette of the concept mapping tool 
The other cognitive tools developed for the prototype were designed to assist learner comprehension of the information presented in the tables and graphs: balloon help; a map; a sorting tool; and embedded questions. These were designed to help the learner to assimilate and organise new information.

\section{Methods}

The study was divided into three linked studies: study 1 focused on cognitive strategies employed by learners as they interpreted graphs and tables; study 2 focused on learner use of the prototype of the cognitive tools and study 3 focused on learner use of the improved cognitive tools.

\section{Study 1: Identifing the cognitive strategies learners employ as they interpreted graphs and tables.}

A review of literature was conducted and it targeted studies related to the difficulties that learners experienced when they attempted to interpret graphs and tables. Then a combined questionnaire and test was administered to a sample of volunteer students from Year 1(n=132), Year $3(n=38)$ and Year $4(n=19)$. The purpose of the questionnaire and test was to identify common errors and to verify the findings from the review of the literature. The test items were selected from an item bank of questions used in the Australian Science in Schools Competition (1988-1994, the University of NSW Education and Testing Centre). They were validated by a panel of science educators from the University of Wollongong and then reviewed by staff at the University of NSW Education and Testing Centre (Wang, M. Personal communication re-selection of test items for Graphs and Tables Test, April 20th, 1995).

Follow up interviews were then conducted with 12 volunteers who completed this test. The purpose of these interviews was to verify data collected by other methods.

\section{Study 2: Learner use of the prototype of the cognitive tools}

The protoype of these tools was trialed with 63 Year 3 preservice teachers and the findings from this trial were used to improve the final version of tools used in study 3. During this trial data was collected from individual journal entries and audit trails of software use. Audit trails (logs of frequency and time) of individual learner use of the software were recorded on a file server. Also 12 volunteers were interviewed after they had used the software. 


\section{Study 3: Learner use of the final version of the cognitive tools}

The findings from study 2 were used to inform design improvements to the final version of the cognitive tools. Audit trails of learner use of the final version of the software were again recorded on a file server. This audit trail data was compared with data other sources such as individual journals, interviews with 12 volunteers and researcher observations of software use. These researcher observations were recorded on a voiceactivated micro cassette audio recorder taken to all laboratory sessions.

\section{Results}

\section{Study 1: Identifing the cognitive strategies learners employ when they interpreted graphs and tables}

Part of the investigation involved administering a multiple-choice test to 132 Year 1, 38 Year 3 and 19 Year 4 (science graduates) in order to compare their ability to interpret graphs and tables. No differences were found between the performances of the Year 1 and Year 3 preservice teachers who were enrolled in the same degree. It appeared that formal studies in education had no measurable effect on the ability of preservice teachers to interpret graphs and tables. However preservice teachers who have completed an undergraduate science degree prior to commencing the teacher education program were better at interpreting graphs and tables than those who have not completed such a degree. Since the Year 4 group had completed formal tertiary studies in science, it would be expected that they would have better developed skills in interpreting graphs and tables than education students.

Item analysis of errors showed that the main difficulties encountered were: deciphering the labels on axes and the headings of columns; describing the global features of the data such as maxima, minima, slope, turning points, regular trends or the means of data presentation such as picture form, bars, columns, lines; relating the properties of the graphs and charts to information described in accompanying text; applying prior knowledge to aid in comprehension of the information presented. This verfied the finding of previous researchers such as: Dugdale (1986); Janvier (1978); Mosenthal \& Kirsh (1991); Pinker (1981); Preece (1985).

The interviews were used to develop a greater understanding the cognitive strategies used by preservice teachers when they were interpreting the graphs and tables from the text. The data obtained are discussed under the broad headings of text and tables, and graphs. 


\section{Text and tables}

The context always plays an important part in the interpretation of graphs and tables. An excerpt from Ellon's transcript serves to illustrate this point. When interviewed about a question related to chemical elements she answered she pointed to the text and remarked

If you look at the question it asks you about the greatest number of elements discovered between certain dates. What does this mean? (points to the word 'element').

This shows that it is important that key terms in the text are understood as scientific terms have very specific meanings that may differ from common colloquial usage.

When learners interpret graphs they often have to re-sort values in his/her head and this creates cognitive load which inevitably leads to errors. For example when Alison was discussing a question relating to tables she said 'I had to try and keep the information in my head.'

Graphs

When the preservice teachers examined and interpreted graphs they divided their attention among local features (a specific value or label on an axis) and global features (a rise or fall or change in slope). At times they misinterpreted the graphs because they did not recognise that a relationship existed between a global and a specific local feature. Also they often failed to carefully read the details on axes. However once the researcher directed their attention to the relevant local or global feature most could choose the correct answer. Thus, in many cases, contextspecific support was all that was needed. Other common errors observed were misreading labels and numbers on axes and the failure to comprehend legends.

The findings from study one can be summarised as follows. When preservice teachers interpret graphs and tables, they process and combine many different forms of information. This complex task creates cognitive load as the learner grapples with unfamiliar text, graphs and tables. Another way that cognitive load is created is by split attention. This occurs when the learner is distracted by information that is peripheral to the task at hand. These findings suggest that learners need support to help them identify and process relevant information and the cognitive tools developed for study 2 (the prototype) were designed to provide such support. They are briefly described in table 1 . 
Table 1: The cognitive tools developed for study 2 (trial of the prototype)

\begin{tabular}{|l|l|l|}
\hline Cognitive tool & Purpose & Supporting theory \\
\hline Buttons & $\begin{array}{l}\text { to link the learner to tools } \\
\text { that assist them to process } \\
\text { information and to } \\
\text { provide functional tools }\end{array}$ & $\begin{array}{l}\text { top down, bottom up processing } \\
\text { (Stanton \& Baber, 1992) }\end{array}$ \\
\hline Balloon help & $\begin{array}{l}\text { to provide "just in time" } \\
\text { support }\end{array}$ & $\begin{array}{l}\text { Electronic performance support } \\
\text { (Gery, 1989) }\end{array}$ \\
\hline $\begin{array}{l}\text { The sorting } \\
\text { tool }\end{array}$ & to reduce cognitive load & $\begin{array}{l}\text { Cognitive load theory (Sweller \& } \\
\text { Chandler, 1994) }\end{array}$ \\
\hline $\begin{array}{l}\text { The embedded } \\
\text { questions }\end{array}$ & $\begin{array}{l}\text { to encourage deeper } \\
\text { processing of information }\end{array}$ & $\begin{array}{l}\text { top down, bottom up processing } \\
\text { (Stanton \& Baber, 1992) }\end{array}$ \\
\hline $\begin{array}{l}\text { The concept } \\
\text { map creation } \\
\text { tool }\end{array}$ & $\begin{array}{l}\text { to act as a knowledge } \\
\text { construction tool }\end{array}$ & $\begin{array}{l}\text { Meaningful learning, (Ausubel, } \\
\text { 1968, Novak \& Gowin, 1984) } \\
\text { Constructivist learning, (von } \\
\text { Glasersfeld, 1989; Jonassen, 1996.) }\end{array}$ \\
\hline
\end{tabular}

\section{Study 2: Learner use of the prototype of the cognitive tools}

The data indicated that the preservice teachers did not have difficulty using the cognitive tools designed for analysis of information (linked to the text, graphs and table). They required minimal instruction and most preservice teachers understood how to use them after one demonstration.

The concept mapping tool was a more complex tool to learn as it also involved learning a procedure, but a one hour demonstration followed by a one hour tutorial/practice session was all that was needed for preservice teachers to become independent users of the tool. The use of computer projection facilities to demonstrate the use of the tool to model the concept mapping process proved to be a powerful way to introduce the tool to a mass audience. In particular the preservice teachers liked the process of joint construction. During this process the researcher and the audience jointly constructed a concept map. The researcher "thought out loud" (articulated his thoughts) as he created a specific concept map suggested by the preservice teachers. Throughout the process the preservice teacher audience were encouraged to assist and to make suggestions that improved the concept map. The benefit of this approach was that it made explicit the cognitive processes used by the demonstrator. 
The following quote is an example of a typical journal entry:

The concept making tool was easy to learn. We probably didn't need to spend one tutorial practicing as I was sure that I'd manage after the lecture...

While it may have been easy to learn to use the concept mapping tool, the cognitive processes involved in synthesising information are more complex and require practice. Thus use of the concept mapping tool may soon become obvious, but the process of synthesising knowledge into a powerful integrated structure takes time to learn and requires the learner to spend time away from the computer to find more information and to construct meaning.

\section{Improving the prototype}

Trials with the prototype identified specific improvements that could be made to the tools. The improvements are summarised in table 2 below.

Table 2: Features added to the improved version of the cognitive tools

\begin{tabular}{|l:l|}
\hline Feature & Function \\
\hdashline $\begin{array}{l}\text { On/off button for } \\
\text { balloon help }\end{array}$ & turns balloon help on and off \\
\hdashline Map link & shows the location on a world map of the \\
\hdashline $\begin{array}{l}\text { Revised palette of } \\
\text { concept mapping } \\
\text { tools }\end{array}$ & the tools buttons are arranged in a left to right \\
\hdashline $\begin{array}{l}\text { Expanding box } \\
\text { around concept label }\end{array}$ & the tools in the trial version of the prototype \\
\hdashline $\begin{array}{l}\text { Horizontal } \\
\text { arrangement of the } \\
\text { buttons }\end{array}$ & places no restriction on the size of the concept \\
\hdashline Save to disc function & this creates more screen space for the concept \\
& allows subjects to save their concept map to a \\
& floppy disc, so that they can keep a copy of their \\
work.
\end{tabular}


The audit trail data showed that when preservice teachers were constructing a concept map to summarise their graph and tables most referred to the table, graph or glossary to gain additional information. Data from interviews and journals showed that the tables confirmed these trends. The following interview transcript serves to illustrate this point:

\begin{abstract}
because you find out exactly what it means at the point of need but you'd need someone to explain that you can click on to those words ... it's a great idea cause it's hitting you right when you need it. Go to the understanding straight away.
\end{abstract}

While audit trail data provides information about the time and frequency of use of the cognitive tools, it can be misleading as it does not take into account times when learners are off-task. Therefore, it is important to use other sources of data and to have an observer present. Such a procedure was used during this study to identify any irregularities in the use of the software.

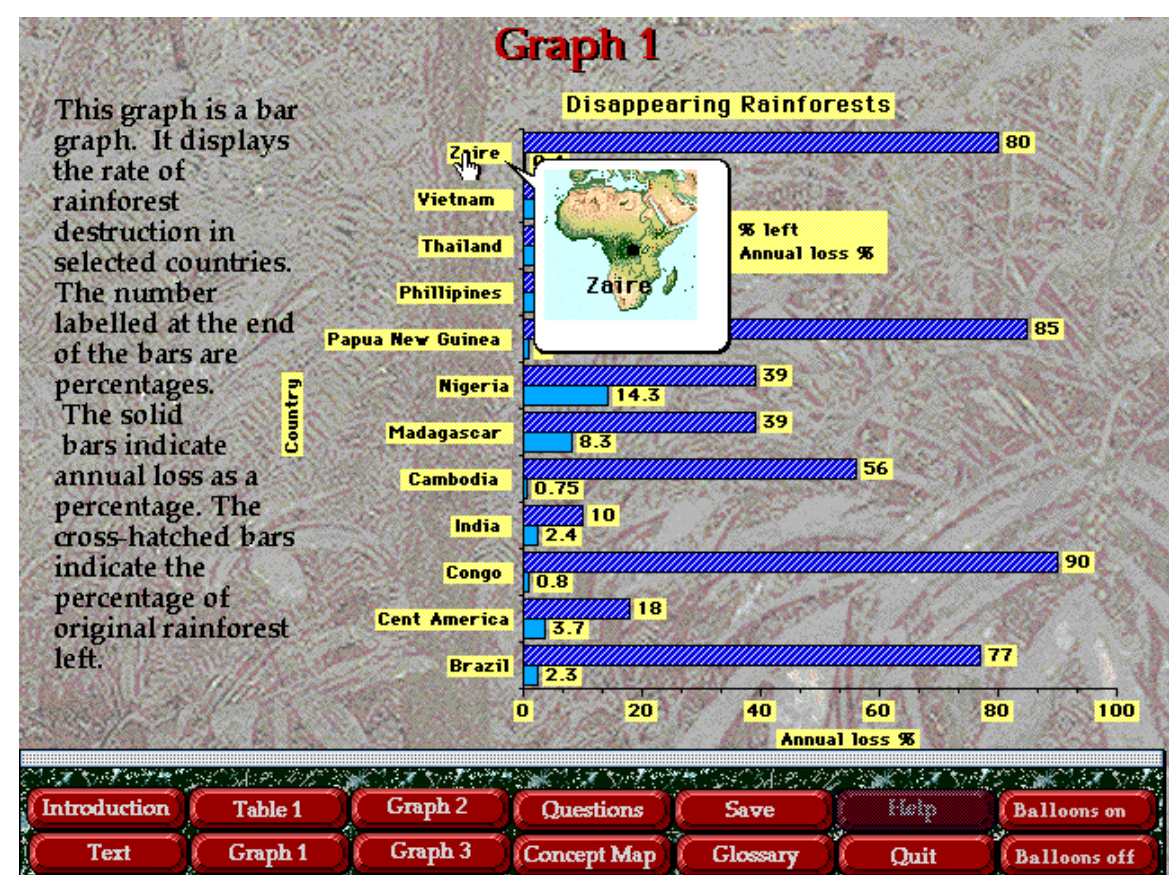

Figure 3 : The improved balloon help for the graphs 


\section{Study 3: Learner use of the final version of the cognitive tools}

Study 3 was designed to investigate preservice teacher use of the redesigned cognitive tools and the findings from study 2 were used to guide the improvements made to the cognitive tools. The improved version of the application is illustrated in the following captured screens.

The improved tools for interpreting graphs are shown in figure 3. It shows how the balloon help feature displays the location of a country when the cursor is located over the name of the country. In this figure the location of Zaire is displayed.

Preservice teacher responses to the glossary, table, graph and concept mapping cognitive tools are now discussed under these headings.

\section{Glossary}

Typical interview responses to the glossary tool follow. Julie stated "I knew that I could simply click on a word in there and I got it explained straight away". Eight of the 12 preservice teachers interviewed mentioned that they used the glossary when they constructed their concept maps. Thus the glossary was acting as a tool that provided "just in time support" as described by Gery (1994).

\section{Table}

The table displayed a set of figures relating to rainforest depletion. The figures in each column could be sorted in ascending order when the user clicked on the words in the heading. All preservice teachers mentioned this feature and most realised that it was a tool that helped them to process information.

Julie explained it as follows:

It un-jumbles and sorts it and I think that makes it clearer to be able to understand it and accentuates it.

Graphs

The graph is supported by balloon help which is activated when the cursor is located over the names on the axes labelled "countries" and the numbers at the end of the bars in the graphs. The balloon help on the axes labelled "countries" provides a small coloured map that displays the location of the country in its home continent. The balloon help on the 
numbers provides additional explanatory text about the numbers. This feature can be disabled by clicking on a button labelled "balloons off".

The balloon help on the axes was considered to be a valuable feature but an unexpected comment was that of Chris who admitted that:

I'm terrible at trying to find where the places are, like I can't remember
where they are. Yeh, I think when I first saw it I thought it was a great idea
just because I'm not too familiar where they're supposed to be, especially
Madagascar, Cambodia. Some of the lesser known places, I wouldn't have a
clue where they are.

Kerry supported this view when she said "I can see the picture of Zaire there (points to a map of Africa). I don't know in relation to the rest of the world where it is."

Most students thought that the text associated with the numbers reinforced what the graph displayed. For example Chris said:

It does make the graph more readable, like more user friendly type of thing. And in mine it just highlights what the graph's saying but in a written term rather than a visual term.

While these cognitive tools helped preservice teachers by: reducing cognitive load associated with the sorting and comparing of numbers in table columns; and by providing additional information which assisted in information analysis and encoding, such as the location of the counties mentioned in the text, graphs and table, they also directed learner attention to relevant information.

\section{Questions}

Questions were also supplied on a separate sheet of paper as this avoided the problem of flipping back and forth among screens while accessing the information. However, the questions were worded in such a way that they required the preservice teachers to read the text or glossary and the table or graphs. Even so preferences emerged. Leanne preferred the graphs as a primary source of information and stated:

I initially used graphs because I feel like I can interpret graphs reasonably well and I quite enjoy interpreting graphs.

Helen used the text as her main source of information when answering the questions and she said:

I used the text because I'm a text, I'm a word person, I'm a reader but I backed it up with, if I've got two sources, I'll always back it up so I check because I don't trust myself. So knowing there was a graph I'd read it come to an answer and then check with the graph. 
These comments show that it is sensible to allow learners to access the forms of information that they are most comfortable with.

\section{Concept map}

The concept mapping tool was designed to synthesise information gathered into a.powerful integrated network. Several strategies were used but most preservice teachers referred to the text or glossary as their primary source of information and to the graphs or the table as a secondary source of supporting information. Melinda took this approach and said:

I referred back to the highlighted words because I thought, well, they're more likely to be the key concepts. But yeh, I suppose initially it came from my head but then I wanted to include the things that you had highlighted as well. So it was a combination of them both."

However, Melinda came to this task with a high level of background experience, she had completed three university subjects in environmental education and was a member of a local landcare group. Leanne did not have the same amount of background experience to draw upon and she used a different strategy. As she states "I sort of actually I went back and made notes. I did actually write on a piece of paper."

Adele's needed to access all of the information and as she stated:

I think all of the information is needed to make the map ... because that helps you understand all three parts, all parts really because you're looking at the text and by putting it in tables that helps you understand that and then graphing it helps you get a visual picture I guess.

The reasons why learners accessed the different forms of information varied but some important reasons may relate to: learner preferences for specific forms of information; learner efficiency in processing the information needed; previous experience with the subject matter or preference for specific tools.

At the end of each interview each student was given the opportunity to add further comments about what they had done. Most of the additional comments focused on the use of the concept mapping tool to synthesise information into a meaningful framework. As Julie stated:

It makes it all concise. You can see, its a good summary too, without going into reams of writing which doesn't always appeal and you can just put down the main ideas, those ideas may jog your memory. 
Sally expressed it in a different way when she said:

A concept map actually forces you to think to link the concepts together so if you have the concept map it's actually easier than a summary because you can see the ideas and how they can link them together.

\section{Conclusion}

The findings from study 1: learner interpretion of graphs and tables, supported the research reported by Janvier (1978) and Preece (1985). However, more extensive research is needed into cognitive load theory (Chandler and Sweller, 1991, 1994) as this is a promising avenue of research that can be applied to the design of cognitive tools. In particular, we need to understand how we can reorganise graphical and tabular forms of information so that it is in a form that reduces cognitive load.

The cognitive tools developed acted as simple mental devices to support, guide and extend the thinking processes of learners so that they could more easily understand information presented in text, graphs and tables. These tools were external to the learner and computer-based. They are what Derry and LaJoie (1993) refer to as unintelligent tools as the learner has to provide the intelligence, not the computer. In particular, the responsibility for planning, decision making and self-regulation of the learning lies with the learner (Jonassen, Peck \& Wilson, 1999).

Many of the cognitive tools developed (such as the sorting tool and balloon help) were forms of "just in time" support (Gery, 1994) and helped learners to analyse and process information. They were context-specific, simple to use and required little, or no instruction. Because they were unobtrusive and did not distract learner attention from the main task, they did not split attention and cause additional cognitive load (Chandler and Sweller, 1991). The support could have easily been in spoken information or visual form but it is important to select a form of support that is appropriate to the context rather than opting for a more complex solution. Indeed, a more complex form of support may prove to be counter productive as it may be a distraction and result in additional cognitive load.

The concept mapping tool was a more sophisticated cognitive tool as it was used to synthesise (integrate) the various forms of information into a knowledge map. It engaged learners in higher order thinking skills such as critical thinking, creative thinking and complex thinking (Jonassen, 1996; Jonassen, Peck \& Wilson, 1999; Hyerle, 1996). However more extensive research is needed to understand how these higher order thinking skills 
interact with each other when learners are actively engaged in the process of concept map construction.

Currently there is a great deal of research interest in developing new cognitive tools, but a word of caution needs to be voiced as the next generation of cognitive tools are designed. Hedberg (1989) correctly asserted that the introduction of technology in education has a history of broken promises and poor performance. As a result many teachers and administrators have become wary of visionaries bearing computer-based gifts (Sewell, 1990). Cognitive tools such as those developed during this study should be seen as a support and certain not as a panacea. Also the forms that these tools take in the future will depend on the context and on the understandings that we develop about how learners use cognitive tools.

\section{References}

Appel, I. J. (1973). The relationship between the sequence of graph interpretation skills and the sequence of mathematics skills for kindergarten through ninth grade. Doctoral Dissertation, Fordham University. (Microfilms order no. 73-16004).

Ausubel, D. P. (1968). Educational psychology: A cognitive view. New York: Holt, Rinehart and Winston.

Bowen, M, G. \& Roth, M-W. (1998). Lecturing graphing: What features of lectures contribute to student difficulties in learning to interpret graphs? Research in Science Education 28(1), 77-90.

Chandler, P., \& Sweller, J. (1991). Cognitive load theory and the format of instruction. Cognition and Instruction, 8(4), 293-332.

Decker, W. H., \& Wheatley, P. C. (1982). Spatial grouping, imagery, and free recall. Perceptual and motor skills, 55, 45-46.

Derry, S. J., \& LaJoie, S. P. (1993). A middle camp for (un)intelligent computing: An introduction. In S. P. LaJoie \& S.J. Derry (eds.), Computers as cognitive tools. Hillsdal, NJ: Lawrence Erlbaum Associates.

Dugdale, S. (1986). Pathfinder: A microcomputer experience in interpreting graphs. Journal of Educational Technology Systems, 15(3), 259-280.

Gery, G. J. (1989). Electronic performance support systems. Computer-Based Training Directions, 2(6), 12-15. 
Gery, G. J. (1994). Electronic performance support systems Cambridge, MA: Ziff Communications.

Hedberg, J. G. (1989). The relationship between technology and mathematics education: Implications for teacher education. In DEET (1989), Discipline review of teacher education in mathematics and science (3) (pp. 103-137). Canberra: Australian Government Publishing Service.

Hegarty, M., Carpenter, P., \& Just, M. A. (1991). Diagrams in the comprehension of scientific texts. In R. Bar, M. L. Kamil. P. B. Mosenthal \& P. D. Pearson (Eds.), Handbook of reading research: Volume II (pp. 641-667). White Plains, N.Y.: Longman Publishing Company.

Hyerle, D. (1996). Visual tools for constructing knowledge. Alexandria, Virginia: Association for Supervision and Curriculum Development.

Janvier, C. (1978). The interpretation of complex cartesian graphs representing situations - studies and teaching experiments. Unpublished PhD Thesis. University of Nottingham, U.K.

Jonassen, D. H. (1992). What are cognitive tools?. In M. Kommers, D. H. Jonassen, \& J. Terry Mayes (Eds.), Cognitive tools for learning. Vol. F81 (pp.1-6). Berlin: Springer-Verland in cooperation with NATO Scientific Affairs Division.

Jonassen, D. H. (1996). Computers in the classroom: mindtools for critical thinking. New Jersey: Merrill.

Jonassen, D. H. \& Reeves, T. (1996). Learning with technology: Using computers as cognitive tools. In D. H. Jonassen, (ed.). Handbook of research for educational communications and technology. New York. McMillan.

Jonassen, D. H., Peck, K. L., \& Wilson, B. G. (1999). Learning With Technology: A Constructivist Perspective. New Jersey: Merril.

Mosenthal, P. B., \& Kirsh, I. S. (1991). Understanding documents: information types in nonmimetic documents: A review of Biddle's wipe-clean slate. Journal of Reading, 34(8), 654-660.

Novak, J. D., \& Gowin, D B. (1984). Learning how to learn. New York: Cambridge University Press

Pinker, S. (1981). A theory of graph comprehension (Occasional Paper No. 10). Massachusetts Institute of Technology, Cambridge. Massachusetts: Centre for Cognitive Sciences.

Preece, J. (1985). Interpreting trends in graphs: A study of 14 and 15 year olds. Doctoral Dissertation. University of Nottingham. (Dissertation abstracts UMI HDH 5405). 
Rabinowitz, M., \& Mandler, J. M. (1983). Organization and information retrieval. Journal of Experimental Psychology: Learning, memory and cognition, 9, 430-439.

Roth, M. W., \& Bowen, M. G. (1994). Mathematization of experience in a Grade 8 open-enquiry environment: An introduction to the representational practices of science. Journal of Research in Science Teaching, 31(3), 293-318.

Roth,W-M.\& McGinn, M.K. (1997). Graphing: Cognitive ability or practice? Science Education, 81, 91-106.

Sewell, D. F. (1990). New Tool for New Minds: A cognitive perspective on the use of computers with young children. London: Harvester Wheatsheaf.

Stanton, N., \& Baber, C. (1992). An investigation of styles and strategies in selfdirected learning. Journal of Educational Multimedia and Hypermedia, 1, 147-167.

Sweller, J. (1994). Cognitive load theory, learning difficulty, and instructional design. Learning and Instruction, 4, 295-312.

Sweller, J., \& Chandler, P. (1994). Why some material is difficult to learn. Cognition and Instruction, 12(3), 185-233.

van Reeuwijk, M. (1992). The standards applied: teaching data visualisation. The Mathematics Teacher, 85(7), 513-518.

von Glasersfeld, E. (1989). Cognition, construction of knowledge and teaching. Synthese, 80, 121-140.

White, R., \& Gunstone, R. (1992). Probing understanding. London: The Falmer Press.

Winn, B. (1987). Charts, graphs and diagrams in educational materials. In D. M. Willows \& H. A. Houghton (Eds.), The Psychology of Illustration Volume 1: Basic research: (pp.152-198). New York: Springer-Verlag. 